\title{
Coevolution of foraging behavior with intrinsic growth rate: risk-taking in naturally and artificially selected growth genotypes of Menidia menidia
}

\author{
Susumu Chiba $\cdot$ Stephen A. Arnott $\cdot$ David O. Conover
}

Published online: 9 May 2008

(C) Springer-Verlag Berlin Heidelberg 2008

\section{Erratum to: Oecologia (2007) 154:237-246}

$$
\text { DOI 10.1007/s00442-007-0825-9 }
$$

In the "Discussion" under the heading "Artificially selected genotypes" one paragraph was unfortunately omitted in the conversion process.

The missing paragraph is provided here:

There was a signifcant difference between treatments regarding the frequency with which fear-related behavior was expressed (Fisher's exact test in $2 \times 4$ contingency table, $P=0.002)$. In the absence of food, fear-related behavior was observed in three of the seven NYFG groups and six of the seven SC groups (Tukey's WSD test, $P>0.05)$. However, in the presence of food, no NYFG groups expressed fear-related behavior, whereas six of the seven NYSG groups did (Tukey's WSD test, $P<0.01$ ).

In all seven of the NYFG trials where food was provided, every individual consumed food within $18 \mathrm{~min}$ (mean $\pm \mathrm{SD}, 10.16 \mathrm{~min} \pm 6.68$ ) of reemergence. Feeding was also observed in all of the NYSG trials, although, in four cases, not all of the individuals accessed the food. There was a significant difference between genotypes in the proportion of individuals that fed (two-tailed $t$-test, $t=-2.63, P=0.039$ ).

The online version of the original article can be found under doi:10.1007/s00442-007-0825-9.

S. Chiba $\cdot$ S. A. Arnott $\cdot$ D. O. Conover

Marine Sciences Research Center, Stony Brook University,

Stony Brook, NY 11794-5000, USA

Present Address:

S. Chiba $(\square)$

Department of Aquatic Bioscience,

Tokyo University of Agriculture, Hokkaido 099-2493, Japan

e-mail: s2chiba@bioindustry.nodai.ac.jp

Present Address:

S. A. Arnott

Beckman Center, B305, Stanford University,

Stanford, CA 94305, USA 